\title{
Severe Hypercalcaemia - \\ Chronic Tophaceous Gout as the Responsible Cause?
}

\author{
René Rodríguez-Gutiérrez, ${ }^{1,2}$ Maria Azucena Zapata-Rivera, ${ }^{1}$ Karla Victoria Rodriguez-Velver, ${ }^{1}$ \\ Fernando J Lavalle-Gonzalez, ${ }^{1}$ José Gerardo Gonzalez-Gonzalez and Jesus Zacarias Villarreal-Perez ${ }^{1}$ \\ 1. Endocrinology Division, Department of Internal Medicine, University Hospital 'Dr José E González', Universidad Autonoma de Nuevo León, \\ Monterrey, México; 2. Knowledge and Evaluation Research Unit, Division of Endocrinology, Diabetes, Metabolism and Nutrition, \\ Department of Medicine, Mayo Clinic, Rochester, Minnesota, uS
}

\begin{abstract}
The association of chronic tophaceous gout with severe hypercalcaemia is exceptional. In this case, a 42-year old man with a longstanding history of gout arrived at the emergency room with altered mental status. Laboratory work up revealed a uric acid of $14.0 \mathrm{mg} / \mathrm{dl}$, corrected calcium of $14.5 \mathrm{mg} / \mathrm{dl}$, phosphorous of $6.3 \mathrm{mg} / \mathrm{dl}$, parathyroid hormone (PTH) was suppressed (<3.0 pg/ml), 25-dihydroxyvitamin D $25.2 \mathrm{ng} / \mathrm{ml}$, parathyroid hormone related-protein (PTHrP) was $45.0 \mathrm{pg} / \mathrm{ml}$ and calcitriol $19.6 \mathrm{pg} / \mathrm{ml}$. Biopsy histopathology result showed deposits of monosodium urate crystals surrounded by granulomatous inflammation. The association of chronic tophaceous gout with severe hypercalcaemia is extremely rare and has been usually described to be secondary to 1-25 dihydroxyvitamin D (calcitriol) secretion. In this case, calcitriol levels were normal and this possibility was excluded. On the other hand, PTHrP had never been, until now, described as the responsible cause of hypercalcaemia in gout. In our case, baseline PTHrP and calcium values were elevated and after medical treatment both returned to normal values. PTHrP usually causes hypophosphataemia and in this case the abnormal renal function could have diminished this last effect.
\end{abstract}

\section{Keywords}

Tophaceous gout, severe hypercalcaemia, calcitriol, thopi

Disclosures: René Rodríguez-Gutiérrez, Maria Azucena Zapata-Rivera, Karla Victoria Rodriguez-Velver, Fernando J Lavalle-Gonzalez, José Gerardo Gonzalez-Gonzalez and Jesus Zacarias Villarreal-Perez have no conflicts of interest to declare. No funding was received for the publication of this article.

Compliance with Ethics: Written informed consent was obtained from the patient for publication of this case report and the accompanying images.

open Access: This article is published under the Creative Commons Attribution Noncommercial License, which permits any non-commercial use, distribution, adaptation and reproduction provided the original author(s) and source are given appropriate credit.

Received: 17 May 2015 Published Online: 8 July 2015 Citation: European Endocrinology, 2015;11(2):102-4 DOl: 10.17925/EE.2015.11.02.102

Correspondence: René Rodríguez-Gutiérrez, Endocrinology Division, Department of Internal Medicine, Hospital Universitario 'Dr José E González', Universidad Autonoma de Nuevo León, Monterrey, México. E: renerodriguez@investigacion-meduanl.com; rodriguezgutierrez.rene@mayo.edu

\section{Case Presentation}

Sometimes the worst has to happen before seeking medical attention. This was the case of a 42-year-old man who arrived to the emergency room with altered mental status characterised by lethargy and confusion. His sister referred a long-standing history of gout that was diagnosed 8 years earlier and that was treated irregularly with non-steroidal antiinflammatory drugs (NSAIDS) and colchicine and reported a negative family history of gout. Two years earlier, multiple tophi had appeared on the ears, elbows, hands and foot and 6 months previously he was confined to bed due to intense generalised pain. Despite his family insistence, the patient constantly refused to receive medical attention. A week earlier he referred initiating with polyuria, polypsia and constipation and nausea and vomiting developed 48 hours before admission. Progressive altered mental status finally made his family pursue formal medical attention.

\section{Assessment}

Physical examination revealed altered mental status characterised by lethargy and a Glasgow coma scale of 14 without any signs of focalisation. Blood pressure was $130 / 85 \mathrm{mmHg}$, respiratory rate 13 per minute, heart rate 95 beats per minute, temperature $36.3^{\circ} \mathrm{C}$ and room-air oxygen saturation was $98 \%$. Characteristic, multiple, non-tender tophi from 1 to $6 \mathrm{~cm}$ were obvious at inspection in the wrists, metacarpophalangeal, proximal and distal interphalangeal articulations, elbows, knees, ankles and the first metatarsophalangeal joint (see Figure 1). A non-infected ulcer was seen in the second metacarpophalangeal joint. There were no signs of septic arthritis and the rest of the examination was unremarkable.

Laboratory work up revealed a uric acid of $14.0 \mathrm{mg} / \mathrm{dl}$, corrected calcium of $14.5 \mathrm{mg} / \mathrm{dl}$, phosphorous of $6.3 \mathrm{mg} / \mathrm{dl}$, creatinine of $5.4 \mathrm{mg} / \mathrm{dl}$, blood nitrogen urea of 56 , a Modification of Diet in Renal Disease (MDRD) glomerular filtration rate (GFR) of $16 \mathrm{ml} /$ minute and urinary calcium of $350 \mathrm{mg} / 24$ hours. PTH was suppressed (<3.0 pg/ml), 25-dihydroxyvitamin D was normal, parathyroid hormone related-protein (PTHrP) was $45.0 \mathrm{pg} /$ $\mathrm{ml}$ and calcitriol $19.6 \mathrm{pg} / \mathrm{ml}$. Red blood cell count was normal and a peripheral smear showed no dysmorphic red cells. Twenty-four hour protein excretion was $110 \mathrm{mg} /$ day (see Table 1). An electrocardiogram showed the characteristic shortened QT interval with no other rhythm abnormalities. Radiographs of upper and lower extremities revealed bone erosions with the characteristic 'overhanging' edges (see Figure 1). 


\section{Figure 1: Physical Examination Findings and Description}

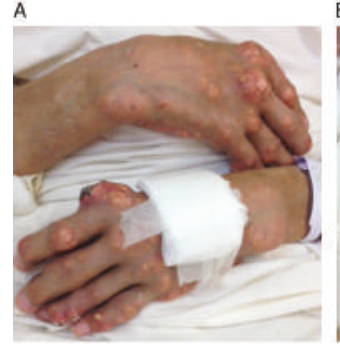

D

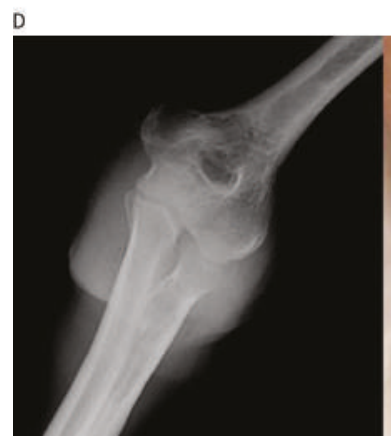

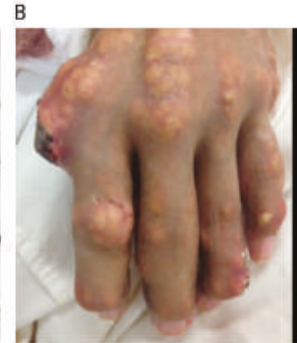
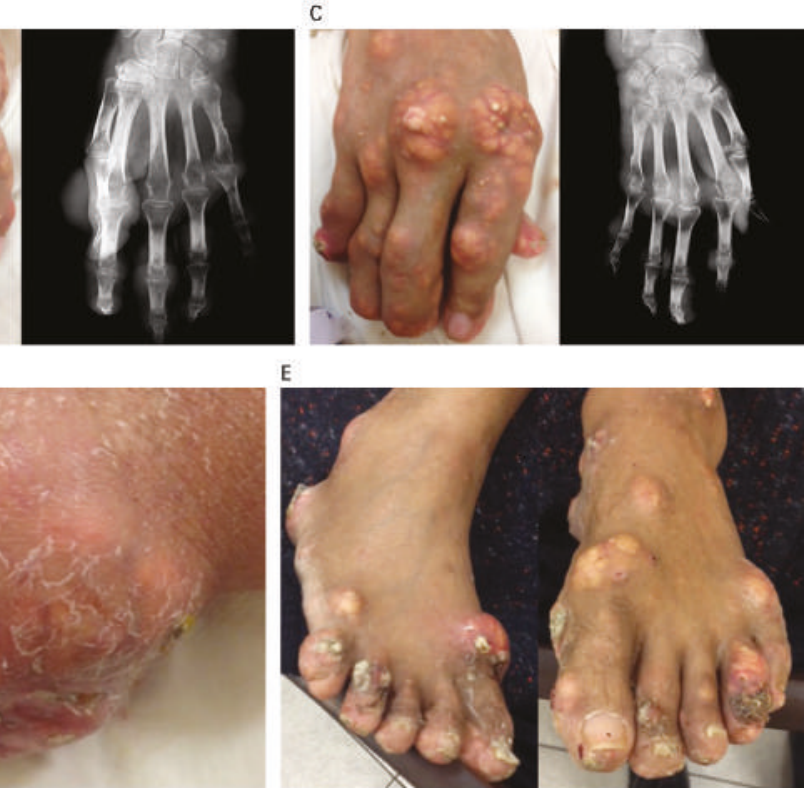

Non-tender tophi from 1 to $6 \mathrm{~cm}$ were obvious at inspection. A-C. Wrists, metacarpophalangeal, proximal and distal interphalangeal articulations. D. Elbows. E. Ankles and first metatarsophalangeal joint. Radiographs of upper and lower extremities revealed bone erosions with the characteristic 'overhanging' edges.

Biopsy histopathology result showed deposits of monosodium urate (MSU) crystals surrounded by granulomatous inflammation.

\section{Diagnosis}

The most common cause of severe hypercalcaemia in a hospitalised setting is malignancy. The responsible mechanisms are known to be secondary to local osteolysis, PTHrP mediated, 1,25-dihydroxyvitamin D $\left(1,25(\mathrm{OH})_{2} \mathrm{D}_{3}\right.$, calcitriol) secretion and ectopic parathyroid hormone (PTH). ${ }^{1}$ PTHrP, as seen in our patient, is the most common cause and has usually been described in non-metastatic solid tumours (bladder, breast and squamous cell tumors) and non-Hodgkin lymphomas. In this sense, a bone scan and a positron emission tomography-computed tomography (PET-CT) were negative for metastasis and malignancy. Nevertheless, usually associated with mild/moderate levels of hypercalcaemia, hyperparathyroidism, overall, is known to be the most common cause of hypercalcaemia and was also ruled out. ${ }^{2}$ As causes of secondary hyperucricaemia, drugs and/or diet supplements were excluded, as well as haemolytic disorders, obesity, psoriasis and myeloproliferative and/or lymphoproliferative disorders. There was no family history consistent with an inherited defect that could lead to purine overproduction.

The association of chronic tophaceous gout with severe hypercalcaemia is extremely rare and has been usually described to be secondary to 1-25 dihydroxyvitamin $\mathrm{D}$ (calcitriol) secretion. The proposed mechanism has been an enhanced $1 \alpha$-hydroxylation of vitamin $D$ in a proliferative chronic synovitis with granulomatous inflammation and giant cells (macrophages), with a consequent increase in active calcitriol that results in hypercalcaemia and/or hypercalciuria., ${ }^{3,4}$ In this case calcitriol levels were normal and this possibility was excluded. In addition to this, after treatment with prednisone the levels of calcitriol were no different. On the other hand, PTHrP had never been, until now, described as the responsible cause of hypercalcaemia in gout. In our case, baseline PTHrP and calcium values were elevated and after medical treatment both returned to normal values. PTHrP usually causes hypophosphataemia and in this case the abnormal renal function could have diminished this last effect. Immobilisation is
Table 1: Laboratory Measures

\begin{tabular}{|c|c|c|c|}
\hline Value & Basal & Post-treatment & Range \\
\hline Haemoglobin (g/dl) & 15.8 & 13.5 & $(12-16)$ \\
\hline Haemoglobin (mmol/l) & 9.8 & 8.4 & $(7.4-9.9)$ \\
\hline Uric acid (mg/dl) & 14.0 & 8.2 & $(0-7)$ \\
\hline Uric acid (umol/l) & 832.7 & 487.7 & $(0-416)$ \\
\hline Glucose (mg/dl) & 84 & 82 & $(70-100)$ \\
\hline Glucose (mmol/l) & 4.7 & 4.6 & $(3.9-5.6)$ \\
\hline Creatinine (mg/dl) & 5.4 & 0.8 & $(0.6-1.2)$ \\
\hline Creatinine (umol/l) & 477.3 & 70.7 & $(53-106)$ \\
\hline Urea nitrogen (mg/dl) & 56 & 17 & $(8-23)$ \\
\hline MDRD GFR (ml/minute) & 12.0 & 96.1 & $(\geq 60)$ \\
\hline Albumin (g/dl) & 3.1 & 3.7 & $(3.5-5.0)$ \\
\hline Albumin $(g / l)$ & 3.1 & 37 & $(35-50)$ \\
\hline Calcium (mg/dl) & 14.5 & 9.6 & $(8.2-10.2)$ \\
\hline Calcium (mmol/l) & 3.6 & 2.4 & $(2.0-2.55)$ \\
\hline Phosphate (mg/dl) & 6.3 & 3.7 & $(2.3-4.7)$ \\
\hline Phosphate (mmol/l) & 2.0 & 1.2 & $(0.7-1.5)$ \\
\hline Magnesium (mg/dl) & 1.8 & 2.3 & $(1.5-2.3)$ \\
\hline Magnesium (mmol/l) & 0.74 & 0.95 & $(0.62-0.95)$ \\
\hline Potassium (meq/l) & 3.9 & 4.3 & $(3.5-5.0)$ \\
\hline Urinary calcium (mg/day) & 350 & 150 & $(100-250)$ \\
\hline Urinary protein (mg/day) & 112 & 98 & $(\leq 150)$ \\
\hline Alkaline phosphatase (UI/I) & 175 & 134 & $(50-120)$ \\
\hline PTH (pg/ml) & $<3.0$ & 15.7 & $(1.5-37)$ \\
\hline PTH (pmol/l) & $<0.31$ & 1.66 & $(0.15-3.92)$ \\
\hline PTHrP (pg/ml) & 45.0 & 9.7 & $(14-27)$ \\
\hline PTHrP (ng/l) & 45.0 & 9.7 & $(14-27)$ \\
\hline $25(\mathrm{OH}) \mathrm{D}_{3}(\mathrm{ng} / \mathrm{ml})$ & 25.2 & 27.5 & $(>20)$ \\
\hline $25(\mathrm{OH}) \mathrm{D}_{3}(\mathrm{nmol} / \mathrm{l})$ & 63.9 & 68.6 & $(>49.9)$ \\
\hline $1,25(\mathrm{OH})_{2} \mathrm{D}_{3}(\mathrm{pg} / \mathrm{ml})$ & 19.6 & 23.7 & $(18-38)$ \\
\hline $1,25(\mathrm{OH})_{2} \mathrm{D}_{3}(\mathrm{pg} / \mathrm{ml})$ & 47.0 & 56.9 & $(43.2-91.2)$ \\
\hline
\end{tabular}

$1,25(\mathrm{OH})_{2} D_{3}=1,25$-dihydroxyvitamin $\mathrm{D} ; 25(\mathrm{OH}) \mathrm{D}_{3}=25$, Hydroxyvitamin $\mathrm{D} ; \mathrm{LDH}=$ lactate dehydrogenase; MDRD GFR = Modification of Diet in Renal Disease glomerular filtration rate; $P T H=$ parathyroid hormone; $P$ THrP = parathyroid hormone related protein . 
another well-known cause of mild calcium elevations. ${ }^{5}$ It is likely that in this case this was an exacerbating rather than the primary factor. Local osteolysis was considered but even in advanced rheumatoid arthritis and other severe causes of bone erosions, hypercalcaemia has never been reported.

\section{Management}

Now rarely seen, chronic tophaceous gout represents the last stage of the natural history of gout. It is characterised by collections of solid urate in connective tissues such as cartilage, bursae, soft tissues, tendons, ligaments and enthesis. It is composed of deposits of MSU crystals that are usually surrounded by granulomatous inflammation. ${ }^{1}$ Although clinical signs of acute inflammation sometimes occur in tophi, this is unusual; swelling accompanying a tophus is most often due to the mass of crystals itself. ${ }^{2}$

Treatment was initiated with calcitonin, hydration with intravenous saline solution at $250 \mathrm{ml} /$ hour and prednisone with a consequent improvement in renal function and normocalcaemia restoration. ${ }^{6}$ PTH, 25-dihydroxyvitamin D, PTHrP and calcitriol returned to normal values and after 3 weeks, the patient was discharged with prednisone, NSAIDs and colchicine. At 6 months follow-up the tophi had improved, calcium levels were within the normal range and no pain was reported. In this case the overproduction of PTHrP and the immobilisation were the responsible mechanisms of the hypercalcaemia that was restored after prompt and optimal treatment.

Neogi T, Gout, N Engl J Med, 2011;364:443-52.

management of primary hyperparathyroidism, J Clin Endocrinol Metab, 1996;81:2036.

Sachdeva A, Goeckeritz BE, Oliver AM, Symptomatic hypercalcemia in a patient with chronic tophaceous gout: a case report, Cases J, 2008;1:72.

Ueckermann V, A challenging case of hypercalcaemia, JEMDSA, 2013;18:68-70.

Lee KA, Yoo WH, Immobilization hypercalcemia-associated acute renal failure in a patient with chronic tophaceous gout, Ren Fail, 2009:31:855-7.

6. Khanna D, Fitzgerald JD, Khanna PP, et al., 2012 American College of Rheumatology guidelines for management of gout. Part 1: systematic nonpharmacologic and pharmacologic therapeutic approaches to hyperuricemia, Arthritis Care Res (Hoboken), 2012;64:1431-46. 